\title{
Polo do IEA e sua contribuição para Ribeirão Preto
}

\author{
OSWALDO BAFFA FILHO e ANDRÉ LUCIRTON COSTA
}

\section{Histórico}

$\mathrm{R}$ IBEIRÃo Preto é um município brasileiro, no interior do Estado de São Paulo, distante 313 quilômetros a noroeste da capital estadual, e seu território de pouco mais de $650 \mathrm{~km}^{2}$ abriga uma população de 612.339 habitantes. A cidade, que é conhecida pelos serviços de educação e saúde, é o centro econômico de uma região industrializada que se destaca por sua infraestrura urbana e de transportes.

O campus da USP de Ribeirão Preto teve destacada influência no desenvolvimento regional e do interior do Estado de São Paulo. A formação de quadros de profissionais qualificados criou um centro de referência em educação, com destaque na produção acadêmica e científica, respondendo por 24 cursos de graduação com 28 opções de formação, nas áreas de Exatas, Biológicas e Humanas. As unidades se consolidaram por sua excelência na pós-graduação, com 36 programas de mestrado e 31 de doutorado, responsáveis por cerca de $5 \%$ de toda a produção científica brasileira, documentada na base de dados do ISI. $\mathrm{Na}$ área de extensão, além de muitas outras atividades de apoio, a região possui um hospital universitário com 780 leitos, centro de referência em saúde, e produz pesquisas aplicadas de ponta, além dos atendimentos de alta complexidade. Com unidades isoladas e com autonomia universitária, o campus não possuía uma Unidade voltada à reflexão de questões acadêmicas mais abrangentes e que pudesse gerar ações integradoras dos conhecimentos gerados pelas unidades de ensino e pesquisa e pelos programas científicos.

Os diretores das unidades do campus de Ribeirão Preto estavam empreendendo esforços, desde 1999, para que o IEA estendesse suas atividades ao campus de Ribeirão Preto, com a criação de uma sede local. Apesar de já realizar eventos e algumas atividades de curta duração, esses dirigentes tinham a necessidade de perenizar as atividades do IEA-USP localmente. No ano de 2009, após vários estudos de adequação regimentais empreendidos pelo IEA-USP, que possibilitaram a criação Polos nos diversos campi da USP, aprovou-se a criação da regional de Ribeirão Preto do IEA. O coordenador do Polo é o professor Oswaldo Baffa Filho, da Faculdade de Filosofia, Ciências e Letras de Ribeirão Preto (FFCLRP), nomeado para o cargo no dia 29 de setembro do mesmo ano, a partir de lista tríplice elaborada pelo Conselho Deliberativo do Instituto. Sua inauguração, em local provisório, aconteceu em 4 de novembro de 2009. 
As pesquisas desenvolvidas no campus de Ribeirão Preto ganharam um novo aliado para serem articuladas entre as unidades e divulgadas para a sociedade e comunidade científica. Dadas as características do campus e de sua região de abrangência, foram propostos eixos temáticos iniciais que seriam desenvolvidos com a consolidação das atividades do IEA. Esses eixos temáticos foram: l Saúde Coletiva e da Família; 2 Tecnologia e Inovação em Saúde; 3 Agronegócios e Desenvolvimento Regional; e 4 Educação e Divulgação Científica.

\section{Missão e objetivos}

O IEA tem consciência da relevância de sua missão como unidade da USP. Essa missão consiste em pesquisar e discutir, de forma aprofundada e abrangente, questões fundamentais das ciências (Exatas, Biológicas e Humanas), da tecnologia, das artes e das demais áreas do conhecimento, estimulando a interdisciplinaridade, promovendo a inovação e contribuindo para a análise de questões sociais e a formulação de políticas públicas.

A missão do IEA se insere na definição moderna de Universidade que norteia a USP e que envolve, além do desenvolvimento de cada área do conhecimento, iniciativas para estimular a formação de interfaces e para a análise das questões num contexto social e teórico abrangente e complexo. O Instituto entende que essa missão deva ser levada adiante em estreita colaboração com as Unidades da USP e com outras Universidades e instituições acadêmicas, e que também deva objetivar a inserção de suas atividades num contexto internacional, estimulando a universalidade dos conhecimentos gerados pelas unidades.

Além disso, o IEA de Ribeirão Preto procura promover a extensão e integração das atividades com o IEA campus de São Paulo, mantendo efetiva cooperação e atendendo aos princípios gerais de interdisciplinaridade, multidisciplinaridade, alto nível científico e cultural, além do atendimento aos objetivos regionais acadêmicos e comunitários.

Busca realizar programas e projetos nas áreas do desenvolvimento científico, tecnológico, educacional e cultural, aproveitando-se da sólida base de recursos humanos e institucionais presentes no campus de Ribeirão Preto, bem como ao aprofundamento de temas importantes às comunidades de pesquisadores. A interação com os demais interlocutores locais e regionais também é um dos objetivos do IEA de Ribeirão Preto, nas relações universidade-sociedade como incubadoras de Empresas, Parque Tecnológico, apoio a formulação de políticas públicas de desenvolvimento científico e tecnológico da sociedade brasileira.

\section{Estrutura acadêmica e produção do IEA}

O IEA possui uma estrutura acadêmica que se diferencia das demais unidades da USP e que requer planejamentos e recursos especiais. Ela compreende professores visitantes, professores colaboradores, pesquisadores, grupos de pesquisa, cátedras e convênios.

A produção do IEA consiste em: (1) atividades de estudos dos grupos de pesquisa e dos professores em torno de temas de ponta, com a geração de 
propostas de eventos, documentos e publicações; (2) realização de congressos, simpósios, seminários, palestras; (3) a publicação da revista ESTUDOS AVANÇADOS, de livros, artigos sobre os temas investigados, com destaque para as mídias eletrônicas.

Para realização de suas atividades, o IEA se estruturará para desenvolver projetos, buscar e fornecer auxílios aos pesquisadores e realizar convênios com unidades e com a sociedade. Essa estrutura administrativa deverá dar apoio à articulação de relações de pesquisa e de divulgação entre a comunidade de pesquisa local da Universidade de São Paulo. A estrutura deve potencializar a produção de conhecimento de temas que são transversais às unidades e que possuem objetos com complexidade que demandam especialidades de conhecimento e visões que são encontrados da sinergia do relacionamento entre os campos do conhecimento.

As unidades de pesquisa e ensino do campus de Ribeirão Preto, e sua comunidade de pesquisadores têm dado apoio à consolidação do Polo do IEA. Destaca-se o Centro de Informática de Ribeirão Preto (Cirp) que cede espaço para a sua sede provisória e para a realização de eventos e da Coordenadoria do campus USP de Ribeirão Preto, que ofereceu apoio administrativo para início das operações.

\section{Temas abordados pelo Polo do IEA de Ribeirão Preto}

O Polo do IEA de Ribeirão Preto procura relacionar as pesquisa e os temas gerados pela comunidade científica do campus de Ribeirão Preto com as demandas de estudos nacionais e regionais. Apesar de sua história recente e as atividades de estruturação administrativa do Polo, houve avanços no sentido de consolidar linhas de estudo e o envolvimento da comunidade local nas atividades do Polo. Está em fase de consolidação a criação de grupos de pesquisas em temas específicos, tais como economia de baixo carbono e incorporação de tecnologia em saúde.

Outras atividades foram desenvolvidas em temas sugeridos pela comunidade que teve participação significativa. Os temas abordados são:

- Informação quântica.

- Energia no Estado de São Paulo e sustentabilidade.

- Métrica em sustentabilidade.

- Acúmulo de conhecimento sobre a biodiversidade e estratégias regionais de conservação.

- Pressão intercraniana.

- Desafios para Educação Básica no Brasil

- Queimadas na Amazônia e seus efeitos no ecossistema e na saúde da população

- Política ambiental.

- Parques tecnológicos. 
- Nanotecnologia em carbono e materiais relacionados.

- Modelagem econômica para o estudo de políticas climáticas, biocombustíveis e mudanças no uso da terra.

- LNLS: passado, presente e futuro.

- Desafios e Propostas para o Brasil em Ciência, Tecnologia e Inovação (CTI) para o Século XXI.

- De ciências, comunicação e futebol: a espiral da cultura científica

- Trinta e sete anos de trabalhos na Serra da Capivara - Piauí.

- Mudanças climáticas globais e o papel do Brasil.

- O CNPq e o Sistema de C\&T do Brasil: desafios e oportunidades $(24 / 6 / 2010)$.

- Novas formas de organização acadêmica: o exemplo da Each-USP.

\section{Projetos para o futuro}

O Polo do IEA de Ribeirão Preto busca articular a comunidade de pesquisa do campus para dar soluções às complexas demandas da sociedade brasileira e da comunidade acadêmica. Busca potencializar a influência da Universidade para a comunidade local e nacional, levando as pesquisas da academia para a sociedade e trazendo os problemas para os quais a sociedade gostaria de encontrar soluções. Com essa introdução, é importante estruturar administrativamente o Polo do IEA com a criação de sua sede própria, projeto estratégico, já acordado com as unidades do campus de Ribeirão Preto e tratado como prioridade de gestão. Na sede de Ribeirão Preto, haverá espaço para auditório e para abrigar professores convidados e pesquisas institucionais.

Nesse sentido, pretende-se trazer para a Universidade questões sobre o desenvolvimento intelectual, econômico e social. Materializando esses objetivos, estão sendo criados - e deverão ser mantidos - grupos de pesquisas de temas que não são comuns às unidades de ensino e pesquisa. Dois grupos já estão se formando em economia de baixo carbono e na área de incorporação e avalição de tecnologia na área de saúde.

A criação de cátedras também é projeto do Polo para trazer pesquisadores internacionais temporariamente estabelecidos em Ribeirão Preto, para colaborarem em projetos específicos. Além disso, haverá continuidade do projeto de divulgação das atividades e de pesquisa em seminários específicos de interesse da comunidade acadêmica. Junto com mecanismos de divulgação para a grande mídia, como informativos, comunicados à imprensa, atualização e manutenção de mídias eletrônicas, entre outras atividades que serão possíveis graças à chegada de funcionários contratados para o Polo do IEA de Ribeirão Preto.

A pesquisa complexa, potencialmente útil à sociedade, é o principal produto que o Instituto de Estudos Avançado da Universidade de São Paulo, junto com as unidades do campus de Ribeirão Preto, pretende colaborar com o desenvolvimento do país e da Universidade. 
Oswaldo Baffa Filho é professor titular do Departamento de Física e Matemática da USP-RP e coordenador do Polo IEA-RP. @- baffa@usp.br

André Lucirton Costa é professor associado do Departamento de Administração da Faculdade de Economia, Administração e Contabilidade de Ribeirão Preto (FEA-RP) da USP e vice-coordenador do Polo IEA-RP. @ - alcosta@usp.br

Recebido em 30.9.2011 e aceito em 5.10.2011. 
